\title{
REFURBISHMENT AND TESTING OF THE 1970'S ERA LASS SOLENOID COILS FOR JLAB'S HALL D
}

\author{
R. Anumagalla (deceased), J. Ballard, G. Biallas, P. Brindza, T. Carstens, J. \\ Creel, H. Eglyan, F. Martin, Y. Qiang, S. Spiegel, M. Stevens, M. \\ Wissmann, and E. Wolin \\ Thomas Jefferson National Accelerator Facility \\ Newport News, VA, 23606, USA*
}

\begin{abstract}
JLab refurbished the LASS [1], $1.85 \mathrm{~m}$ bore Solenoid, consisting of four superconducting coils to act as the principal analysis magnet for nuclear physics in the newly constructed, Hall D at Jefferson Lab for the GLUEX Experiment [2]. The coils, built in 1971 at Stanford Linear Accelerator Center and used a second time at the MEGA Experiment [3] at Los Alamos, had electrical shorts and leaks to the insulating vacuum along with deteriorated superinsulation \& instrumentation. Root cause diagnosis of the problems and the repair methods are described along with the measures used to qualify the vessels and piping within the Laboratory's Pressure Safety Program (mandated by 10CFR851). The extraordinary refrigerator operational methods used to utilize the obsolete cryogenic apparatus gathered for the off-line, single coil tests are described.
\end{abstract}

KEYWORDS: refurbish, repair, solenoid, magnet, test, 10CFR851, leak, short

\section{INTRODUCTION}

As part of the $12 \mathrm{GeV}$ Upgrade to the CEBAF accelerator at JLab a new Hall D is being constructed to accept a $12 \mathrm{GeV}$ Photon beam. The principle analysis magnet for this hall is a superconducting solenoid made from the LASS Solenoid built at Stanford Linear Accelerator in 1971. The original solenoid consists of four coils run at $1600 \mathrm{~A}$, embedded in flux return iron rings. FIGURE 1. The MEGA experiment at Los Alamos also used this magnet in a 3-coil configuration from 1993 through 1995. The coils needed extensive

*Notice: Authored by Jefferson Science Associates, LLC under U.S. DOE Contract No. DE-AC0506OR23177. The U.S. Government retains a non-exclusive, paid-up, irrevocable, world-wide license to publish or reproduce this manuscript for U.S. Government purposes. 


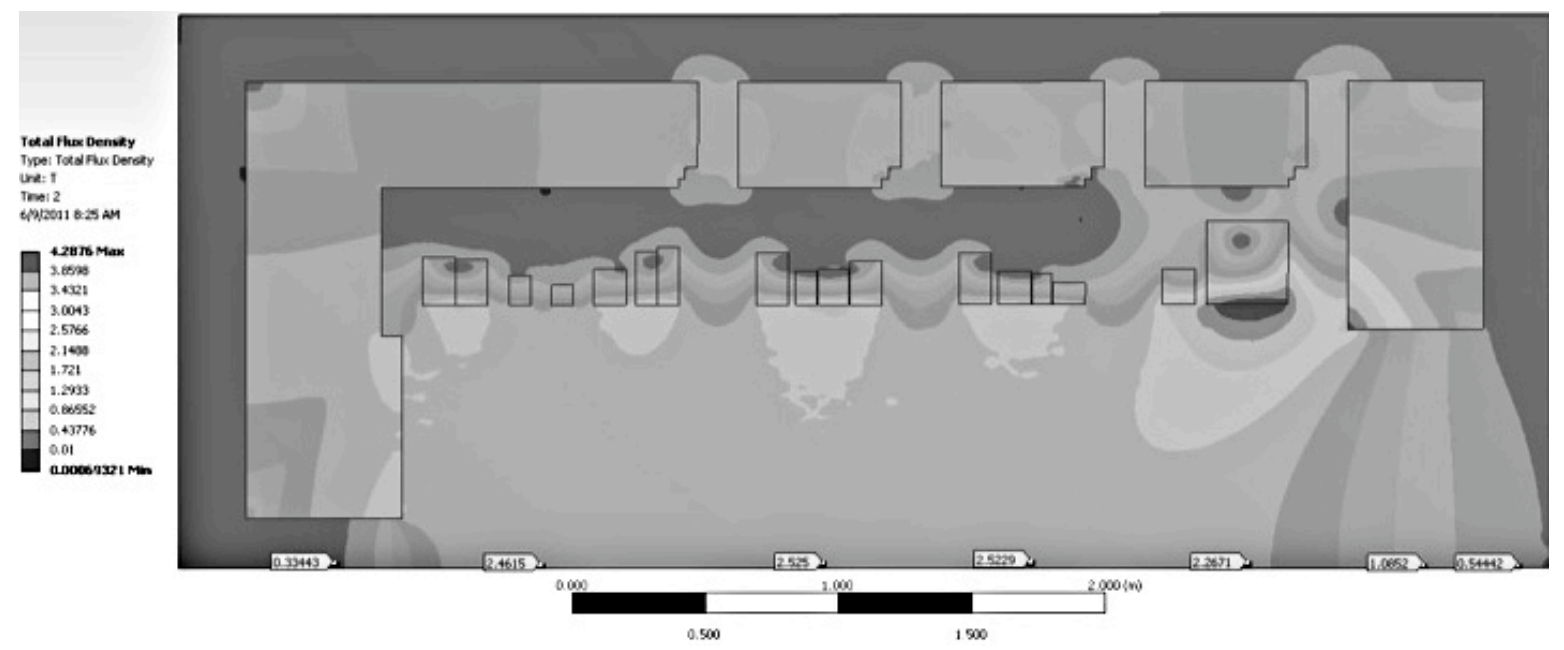

FIGURE 1. Half section magnetic field plot illustrating the SLAC configuration of the LASS Solenoid

repair and refurbishment before they could be relied on to be the principal analysis magnet of the new Hall and the GLUEX Experiment. FIGURE 2. In addition, the magnet system has to pass the Laboratory's Pressure Systems Safety Program based on 10CFR851. The Laboratory's own management as well as reviewers insisted on a full current test (that means full cryogenics) of the individual coils to proof the coils.

\section{Repair and Refurbishment Requirements}

The magnet coils FIGURE 3 came with shorts to ground in two coils, nitrogen circuit

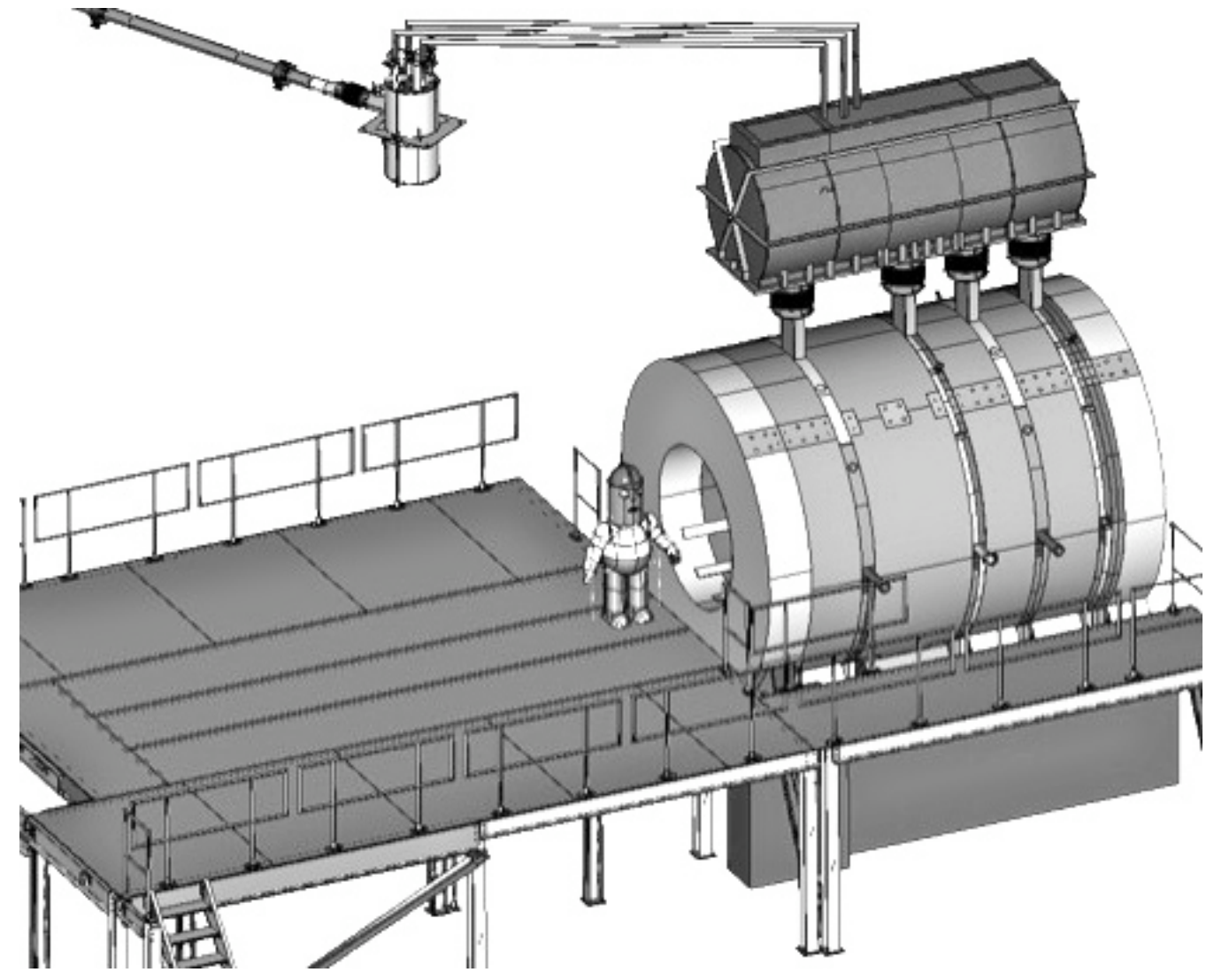

FIGURE 2. Hall D configuration of LASS Solenoid (experiment's detectors removed) 


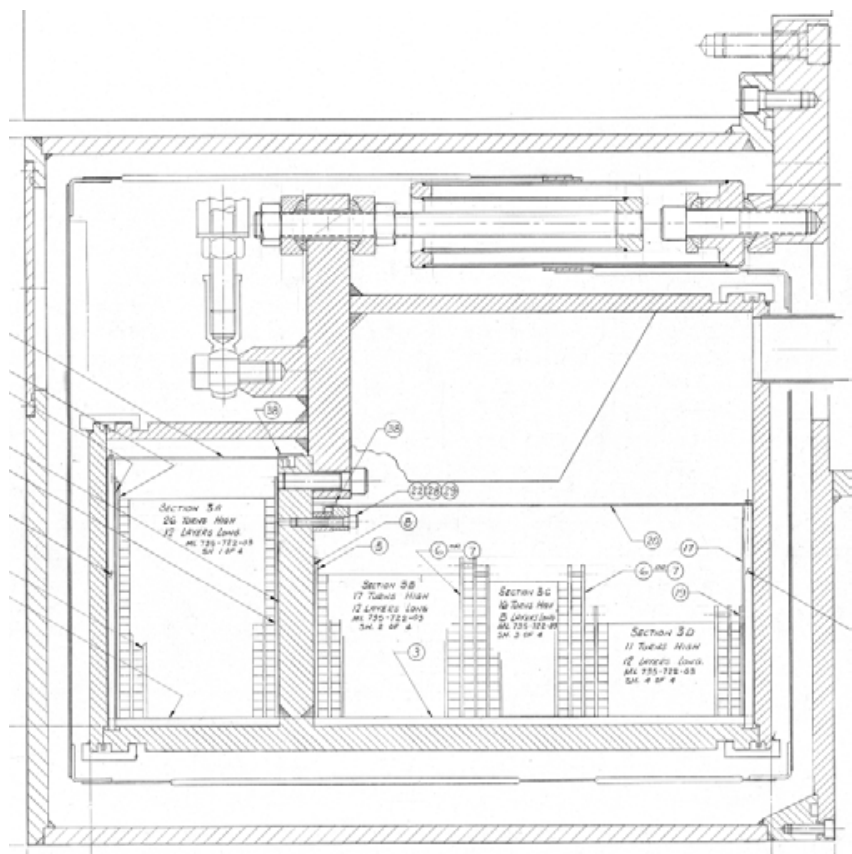

FIGURE 3. Typical coil cross section (Coil 2 shown)

leaks in two coils and a helium leak in another. Superinsulation (NRC2) was in bad shape, much of the aluminum corroded away from the Mylar ${ }^{\mathrm{tm}}$. Instrumentation, strain gauges on the support columns and thermometry on the shields and helium vessel was also not functional and needed replacement.

\section{FIXING ELECTRICAL SHORTS}

Several shorts to ground were "burned out" by a "megger" at SLAC. The root cause of shorts to ground (and the one turn-to-turn short discovered in Coil 1) is that the individual rectangular conductors, $7.62 \mathrm{~mm}(0.300 \mathrm{in}$.) high and $6.35 \mathrm{~mm}(0.250 \mathrm{in}$.) thick, are not wrapped in full insulation. Rather, they are co-wound in a pancake with a $7.62 \mathrm{~mm}$ (0.300 in.) inch wide, three-component spacer consisting of a pre-tensioned, $0.63 \mathrm{~mm}$ (0.025 in.) thick, stainless steel strip with one $0.19 \mathrm{~mm}$ (0.0075 in.) Mylar $^{\mathrm{tm}}$ strip on each side as an electrical insulator. This method leaves the side faces of the pancake uninsulated. Stacks of pancakes form the coil. (Figure 4) The pancakes are separated from each other and from ground by an egg crate like system of radial $2.36 \mathrm{~mm}$ (0.093 in.) spacer strips covering about a forth of the exposed conductor area or $6.35 \mathrm{~mm}$ (0.250 in.) thick spacers at the bobbin I.D. Compounding the tendency to short is that in some zones, the coil-facing surfaces of the coil bobbin were not faced with sheet insulation to isolate the ground surface from the windings. As far as we can tell, the shorts are caused by steel wool-like metallic fibers (from the original winding or cryogenic piping?) and solder balls dropped from solder connections. We discovered both materials when we opened up 3 of the 8 coil vessel cavities. We used a capacitive discharge technique to burn out several other shorts that appeared during handling in Coils 2 and 3.

About half of the pancakes in two coils we examined at JLab have the co-wound stainless steel strips shorted to their conductor in the pancake. This doesn't cause a problem. But, a design error allows the stainless steel strip to work itself out of the pancake on the innermost turn of the outer-most pancake. This displacement caused a short to ground in Coil 4 (repaired at SLAC) and in Coil 3 (repaired at IUCF). Similar but 


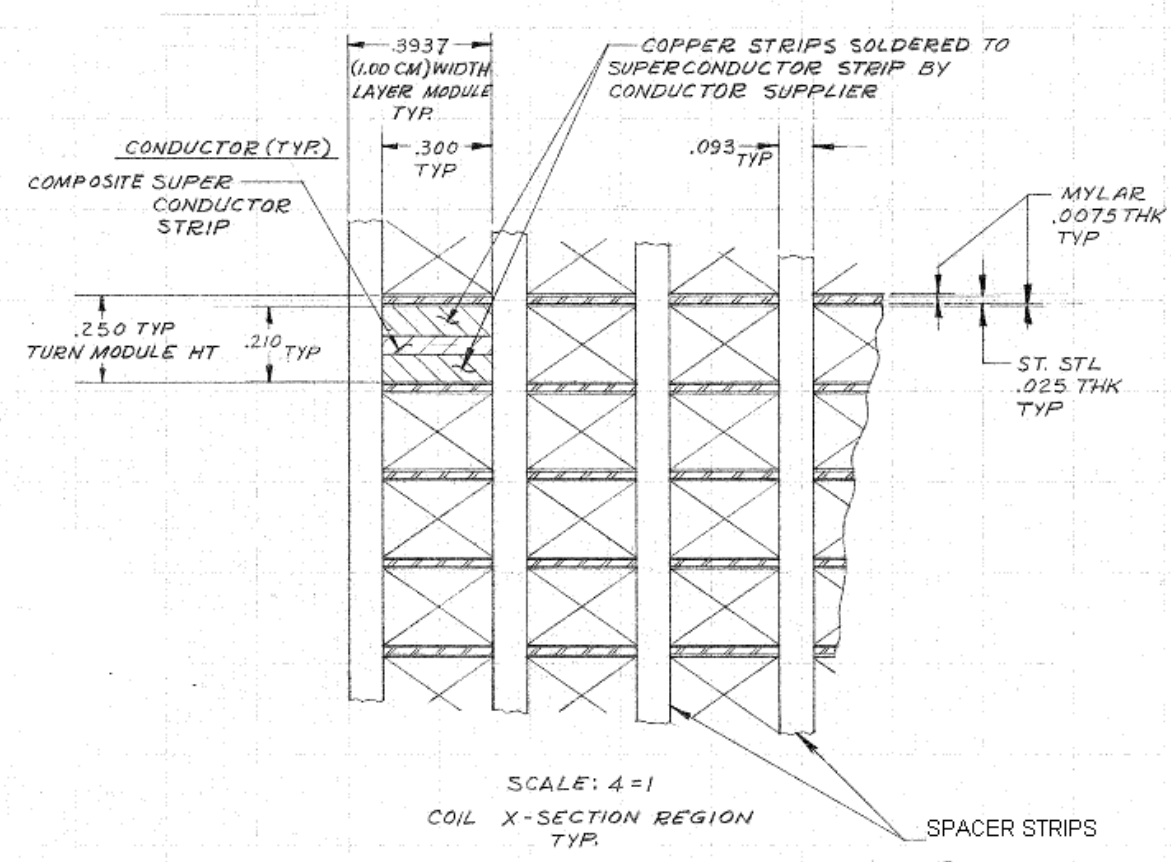

FIGURE 4. Coil construction detail

un-shorted strip motion was found in Coils 1 and 2 and repaired. Coil 1 had a short between an un-insulated power lead and a metallic part of the coil compression system. Coil 2 developed a short between a buckled stainless strip and the inner bobbin. We repaired a local fused zone of copper-stainless steel-copper that formed a turn-to-turn short on the upstream most pancake of Coil 1.

All shorts are repaired and, we conclude, are a result of the root cause above. The coils remain vulnerable. Transporting or powering the coils could shift debris or shift the tensioning strip in the coil cavities that were not cleaned out to bring on a new short. Our fear is that shorts appear that we can't burn out. Note that we can easily operate with one short to ground. (We successfully tested Coil 3 while it was shorted to ground temporarily by a wiring error in the voltage tap leads.) Two shorts form a problematic transformer-like secondary turn. If the turn has resistances in the micro Ohm level, induced high currents and temperatures can cause coil burnout during a rapid dump.

\section{LEAKS TO THE INSULATING VACUUM}

The root cause of the leaks to the insulating vacuum is the use of chloride-based fluxes during the brazing or soldering of stainless steel to copper parts. Chlorides cause pitting corrosion that bores through stainless steel. The segmented and quilted liquid nitrogen shield panels FIGURE 5 are made of laminated copper connected to one-another using stainless steel tubing (acting as a resistor to prevent large induced currents during rapid discharge of the coil) to form the complete shield. We found numerous $1 \mathrm{~mm}$ diameter black spots from flux spatter on the tubing surfaces that were the source of leaks and were welded closed in several coils. This repair method was unsuccessful on the nitrogen shield of Coil 3 after numerous tries. We replaced the shield with a continuous, quilted, all welded stainless steel shield. It was leak tight at its first assembly.

Another source of leaks to the insulating vacuum is laminations in the stainless steel material itself. A zone in the portion of the outer shell of Coil 2's helium vessel had such a 


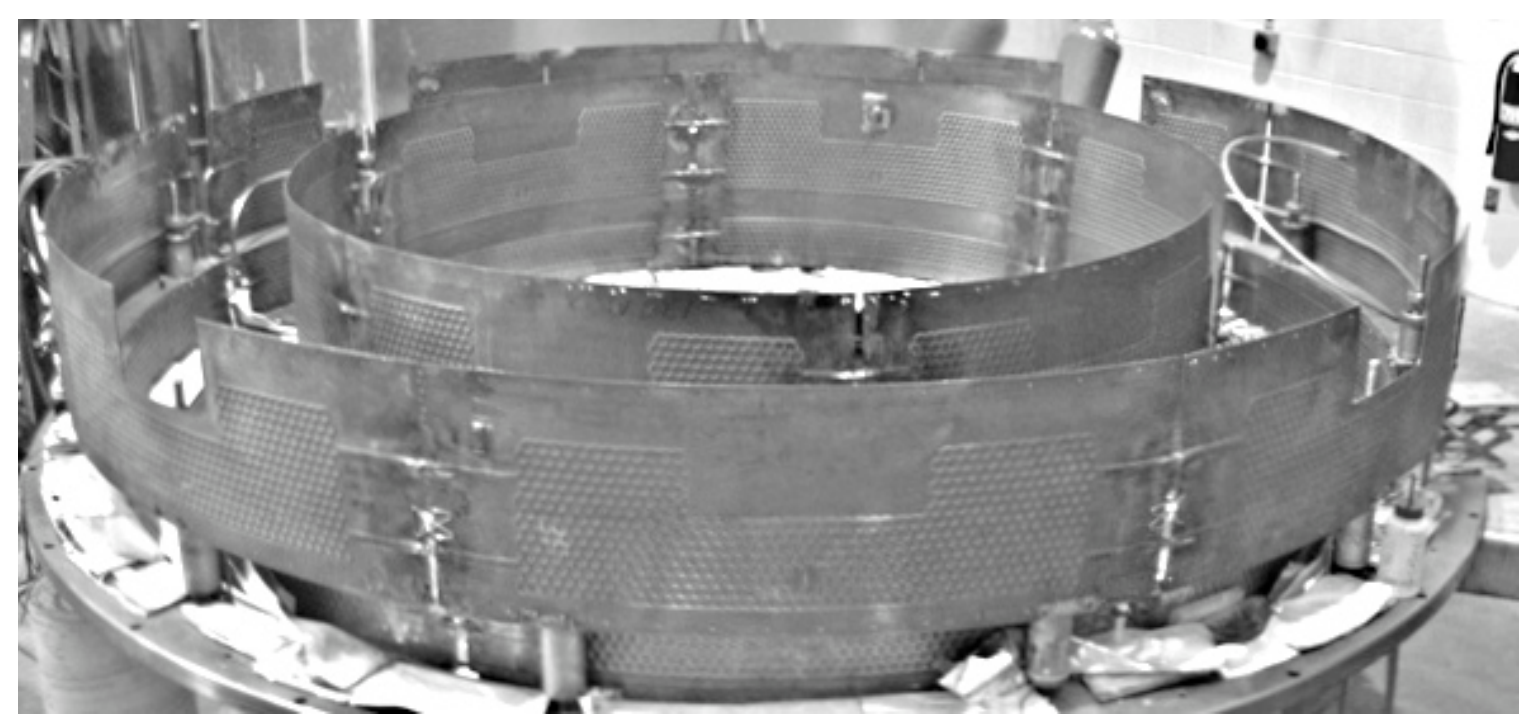

FIGURE 5. LN2 shield panels (Coil 3 shown)

leak from an edge on the interior through to a machined grove on the exterior. We welded it shut. Another lamination leak was from the inner edge of the main vacuum vessel flange to the $4^{\text {th }}$ thread of a blind tapped hole. We used a modified, high strength bolt to close the gap and anaerobic resin based pipe thread dope to seal this leak.

\section{LEGACY SYSTEM INTO THE LAB'S PRESSSURE SYSTEM PRGRAM}

The coil's annular coil vessels were designed to operate at low pressures, a maximum allowable working pressure of $207 \mathrm{kpa}$ (30 psi) absolute and not built to ASME standards. Even though it is a legacy system, it must conform to the mandates of 10CFR851. We agree that $207 \mathrm{kPa}$ (30 psi) is an appropriate maximum allowable working pressure (MAWP) except for the pressure experienced during a significant loss of vacuum (LOV) incident. The worst-case calculation, using $6000 \mathrm{~W} / \mathrm{m}^{2}$ heat input through superinsulated surfaces, causes Coil 1's vessel to experience a spike as high as $517 \mathrm{kPa}$ (75 psi). The 26.3 $\mathrm{mm}$ ( 2 in.) diameter relief tubes are too small to get the helium inventory out fast enough.

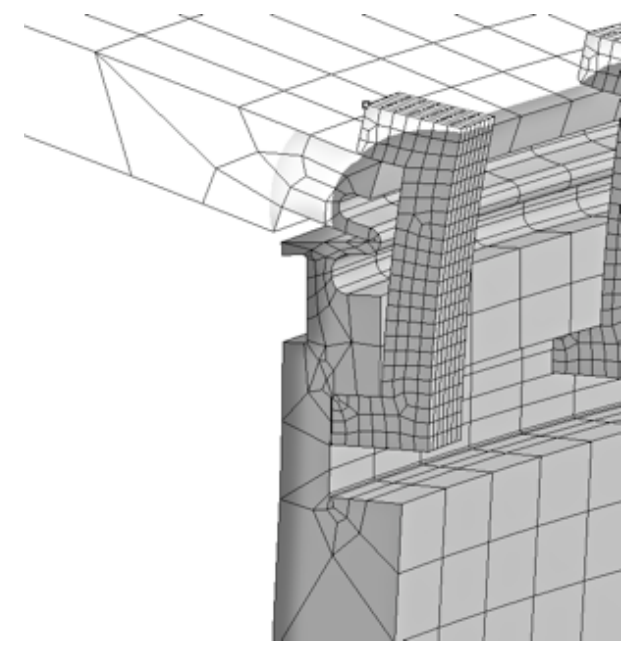

FIGURE 6. FEA analysis illustration of helium vessel shell to flat head joint 
Compounding the problem is that the vacuum type corner seal welds and mechanical clip re-enforcement at the helium vessel shell to flat head joints FIGURE 6 are not ASME qualified construction and may experience yielding stresses (in bending) even at MAWP. Finite element, plastic analysis shows that the vessels are not qualified per ASME standards for 30 psi, but will most likely remain intact beyond 120 psi because of higher stainless steel strengths at low temperature.

We were able to fulfill our mandate, per 10CFR851, to justify that the Pressure System has "equivalent protection" to the ASME Code for normal operating pressures and for the LOV overpressure by using the Risk Code Assignment Tool seen in TABLE 1 and the Pressure System Review Process outlined in the JLab Environment, Safety, Health, and Quality Manual Section 3210-T3 [4]. In our Analysis Document [5] we judge failure of these vessels under such a LOV incident to be of high consequence level and low probability. The Risk Code is an unacceptable rating of " 3 ".

We worked on mitigations. We first reduced the probability of the LOV over-pressure incident to "Extremely Low". We (1) armored all instrument penetrations and bellows, where a large air leak could be opened into the very robust, mostly $12.7 \mathrm{~mm}(1 / 2 \mathrm{in}$,) thick stainless steel vacuum vessel and (2) placed engineered and administrative controls on the vacuum valves at the pumping ports such that they could not be opened to create an air inrush. We also reduced the Consequence Level of an LOV incident to "Low". We did this by re-defining the Pressure Boundary of the helium system to the Vacuum Vessel, thus allowing a tear leak (Stainless steel tears instead of bursts) of the helium vessel joint. We (1) made sure the vacuum vessel is robust and at the same time has adequate relief so that it doesn't pressurize above $103 \mathrm{kPa}$ (15 psi) during a helium vessel tear as well as (2) eliminated exposure of personnel to the helium blast from the vacuum system reliefs using barriers to entry when liquid helium is in the vessel. These mitigations reduced the Risk Code to "N" for Negligible, which we interpreted as equivalent protection to the risk level the ASME Code provides and thus satisfied the mandate of 10CFR851.

This analysis was then reviewed and signed off by another qualified Design Authority per the mandates of the Jefferson Lab Pressure Systems Program (ESH\&Q Manual Section 6151).

\section{INDIVIDUAL COIL TESTS}

We erected a Test Stand for the individual coils in our Test Lab shown in FIGURE 7. Cryogenic fluids (supply and return LHe and LN2) are available from the refrigerators of the Cryogenic Test Facility (CTF) through a co-axial transfer line with a U-tube

TABLE 1. Risk Code Assignment Matrix from JLab Environment, Safety, Health, and Quality Manual Section 3210-T3

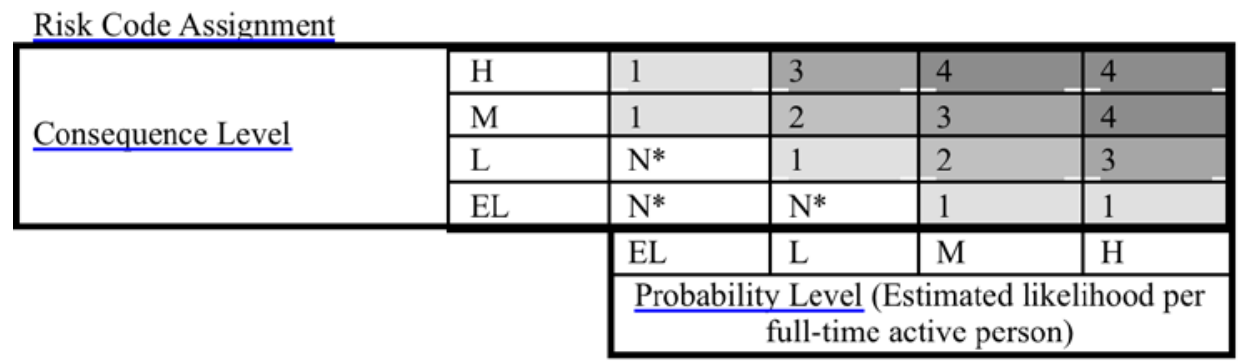

*Negligible Risk 
Distribution Can at the base of the Stand. A $15.8 \mathrm{~m}$ (52 ft.) long, borrowed, co-axial, flex hose based, u-tube called the Anaconda connects the cryogenic U-tube Distribution Can to the Cryo-can and LN2-to-He Heat Exchanger that service the Coil. The Stand allows characterization of the individual coil heat leaks. The power supply with quench detector, dump resistor and the control and data logging system to be used in the Hall are used to power, safeguard and control the coil. The coils are enclosed in their iron yokes in order to evaluate the coil's radial centering and expose the axial support columns to forces expected in the final installation. We also test for evidence of turn-to-turn shorts using a hall probe and test coils placed on the coil axis.

The original plan called for cryogens to be supplied to the magnet Test Stand from a CTI 2800 (200W) located in the CTF. During the initial cool down attempt for Coil 1 it was determined that this refrigerator was not capable of overcoming the combined heat leak of the distribution system, the $52 \mathrm{ft}$ Anaconda, and the load of the coil. U-tubes were changed during the final stages of the Coil 1 cool down switching from the CTI-2800 to a CTI-1400 (500W). This change allowed continuation of the cool down, filling, and testing of the coil. The same method was used for the remaining coil tests. The distribution system design is being carefully considered to eliminate similar issues for the final Hall installation.

To date, three coils were successfully refurbished, cooled and filled to 4.5 Kelvin, and tested to full power. The purpose of the single coil testing was five-fold: (1) identify turnto-turn shorts through magnetic measurements performed under low-power ramping, (2) Operate magnet at full current (1500 A) to evaluate magnet and test power supply and control system, (3) Assess the coil's radial centering (read by strain gauges), (4) Validate structural integrity of the axial coil support columns and (5) estimate the heat leak to the $4.5 \mathrm{~K} \mathrm{LHe}$ circuit and the 80K shield circuit. Findings are summarized in TABLE 2. We are installing the final coil (Coil 2) in the Test Stand for an August test.

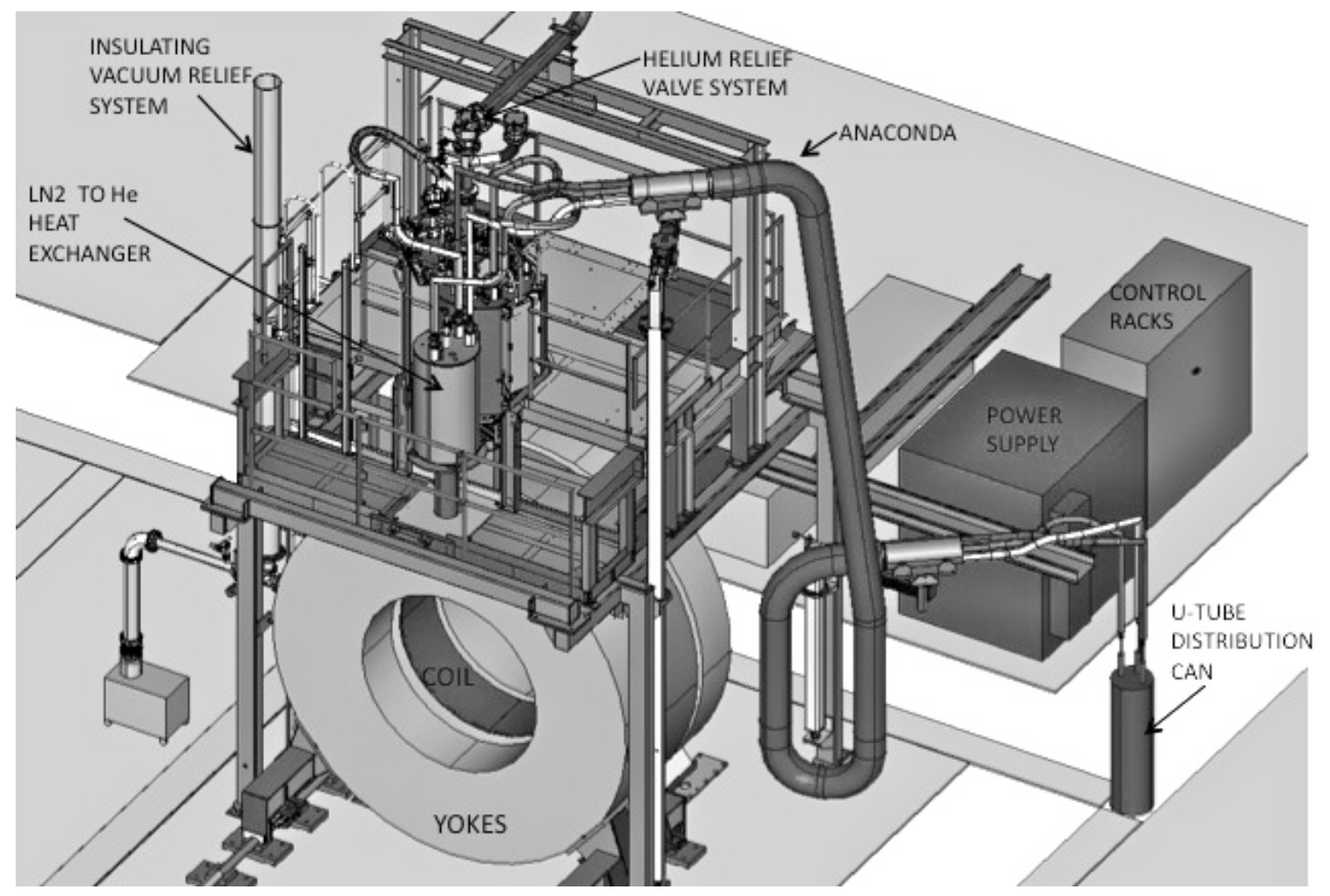

FIGURE 7. Single Coil Test Stan 
TABLE 2. Summary of individual coil test findings

\begin{tabular}{|l|c|c|c|}
\hline & Coil $1\left(1^{\text {st }}\right.$ Test $)$ & Coil $4\left(2^{\text {nd }}\right.$ Test $)$ & Coil $3\left(3^{\text {rd }}\right.$ Test $)$ \\
\hline Turn-to-turn Shorts & None & None & None \\
\hline Maximum Current & $1200 \mathrm{~A}$ & $1500 \mathrm{~A}$ & $1500 \mathrm{~A}$ \\
\hline Radial Centering & Within $5 \mathrm{~mm}$ & Within $13 \mathrm{~mm}$ & Within $5 \mathrm{~mm}$ \\
\hline $\begin{array}{l}\text { Max Axial Force in a Single } \\
\text { Column kN (lb) }\end{array}$ & $\begin{array}{c}7.63(1700) \\
\text { compression }\end{array}$ & $\begin{array}{c}24.2(5,434) \\
\text { compression }\end{array}$ & $45.8(10,300)$ tension \\
\hline Heat Leak to 80K (W) & 195.4 & 404.8 & 202.7 \\
\hline Heat Leak to 4.5K (W) & 23.7 & 34.6 & 31.1 \\
\hline
\end{tabular}

\section{CONCLUSION}

There are no shorts to ground or turn-to-turn shorts in any coil. Hi-pots of the coils in dry air are "open" to the $500 \mathrm{~V}$ range. Above this value we see evidence of a spark gaplike short or excessive increase in current. Because the maximum power supply voltage is 10 volts and maximum discharge voltage is $130 \mathrm{~V}$, there is just enough margin before break down to run successfully. But the electrical integrity remains tenuous, subject to shorting that may or may not "burn out". There are no significant leaks. Cryopumping will maintain the insulating vacuum after initial pump down. Support column strain gauge readings show the coils will successfully suspend within the insulating volume under the magnetic forces. The power supply, quench detector, dump resistor and PLC based control system have improved during each test and are qualified for Hall use. Heat Leak to $4.5 \mathrm{~K}$ is high such that an ultra low heat leak cryogenic service system is needed to match the Stand-alone CTI-2800 Refrigerator.

\section{ACKNOWLEDGEMENTS}

To J. Alcorn and S. St Lorant and the SLAC Team for their pioneering effort in making this magnet, their repair advice and their help in getting documentation. Thanks to Jeffery Self and Robin Swain and the Indiana University Cyclotron Facility for their patient and dedicated refurbishment help.

\section{REFERENCES}

1. The LASS Spectrometer, SLAC-Report-298, April 1986.

2. Physical Review D, Search for the lepton-family-number nonconserving decay $\mu^{+} \rightarrow e^{+} \gamma$, http://link.aps.org/doi/10.1103/PhysRevD.65.112002 date accessed, June 9, 2011.

3. Mapping the Spectrum of Light Quark Mesons and Gluonic Excitations with Linearly Polarized Photons, Presentation to PAC30 - The GlueX Collaboration (Dated: July 6, 2006) http://dustbunny.physics.indiana.edu/HallD/docs/pac30.pdf, date accessed, June 9, 2011.

4. JLab ESH\&Q Manual, http://www.jlab.org/ehs/ehsmanual/index.html, date accessed, June 9, 2011.

5. JLAB Docushare/Facilities Engineering /Pressure Systems/ Pressure Systems Directory (New)/PS-PHY08-005 Hall D Solenoid, https://jlab doc. jlab.org/docushare/dsweb/View/Collection-8988, date accessed, June 9, 2011. 